\title{
Article
}

\section{Tumor microenvironment, HLA class I and APM expression in HPV-negative oral squamous cell carcinoma}

\author{
Claudia Wickenhauser ${ }^{1 \#}$, Daniel Bethmann ${ }^{1 \#}$, Matthias Kappler $^{2 \sharp}$, Alexander W. Eckert ${ }^{2}$, André \\ Steven ${ }^{3}$, Jürgen Bukur ${ }^{3}$, Bernard A. Fox ${ }^{4}$, Jana Beer ${ }^{1}$ and Barbara Seliger ${ }^{3}$ * \\ 1 University Hospital Halle (Saale), Institute of Pathology, Halle (Saale), Germany \\ 2 University Hospital Halle (Saale), Department of Oral and Maxillofacial Plastic Surgery, Halle (Saale), \\ Germany \\ 3 University Hospital Halle (Saale), Institute of Medical Immunology, Halle (Saale), Germany \\ 4 Robert W. Franz Cancer Research Center, Earle A. Chiles Research Institute, Portland, Oregon, USA \\ * Correspondence: barbara.seliger@uk-halle.de; Tel.: +49 (0) 345557 4054; Fax: +49 (0) 3455574055 \\ \# These authors contributed equally to this work.
}

Short running title: Tumor microenvironment and HLA-I expression in HPV-negative OSCC

Simple Summary: Oral squamous cell carcinoma has developed different strategies to escape from $\mathrm{T}$ cell-mediated immune surveillance, which is mediated by changes in the composition of cellular and soluble components of the tumor microenvironment as well as an impaired expression of molecules of the antigen processing machinery leading to a downregulation of HLA class I surface antigens. In depth characterization of these escape mechanisms might help to develop strategies to overcome this tolerance. In this study, human papilloma virus negative oral squamous cell carcinoma lesions were analyzed regarding the protein expression of major components of the HLA class I antigen processing / presentation pathway in correlation to the intra-tumoral immune cell composition, IFN- $\gamma$ signaling and clinical parameters, which was further confirmed by bioinformatics analyses of datasets obtained from The Cancer Genome Atlas. This novel knowledge could be used for optimizing the design of immunotherapeutic approaches of this disease.

\begin{abstract}
Progression of oral squamous cell carcinoma (OSCC) has been associated with an escape of tumor cells from the host immune surveillance due to an increased knowledge of its underlying molecular mechanisms and its modulation by the tumor microenvironment and immune cell repertoire. In this study the expression of HLA class I (HLA-I) antigens and of components of the antigen processing machinery (APM) was analyzed in 160 pathologically classified human papilloma virus (HPV)-negative OSCC lesions and correlated to the intra-tumoral immune cell response, IFN- $\gamma$ signaling and to the patients outcome. A heterogeneous, but predominantly lower constitutive protein expression of HLA-I APM components was found in OSCC sections when compared to non-neoplastic cells. Tumoral HLA-I APM component expression was further categorized into the three major phenotypes HLA-I ${ }^{\text {high }} /$ APM $^{\text {high }}$, HLA-Ilow/APM ${ }^{\text {low }}$ and HLA-Idiscordant high/low/APM ${ }^{\text {high. }}$. In the HLA-Ihigh/APM ${ }^{\text {high }}$ group, the highest frequency of intra-tumoral CD8 ${ }^{+} \mathrm{T}$ cells and lowest number of $\mathrm{CD}^{+} \mathrm{T}$ cells close to $\mathrm{FoxP}^{+}$cells was found. Patients within this group presented the most unfavorable survival, which was significantly evident in stage T2 tumors. Despite a correlation with the number of intra-tumoral CD8 $8^{+}$cells, tumoral JAK1 expression as a surrogate marker for IFN- $\gamma$ signaling was not associated with HLA-I/APM expression. Thus, the presented findings strongly indicate the presence of additional factors involved in the immunomodulatory process of HPV-negative OSCC with a possible tumor-burden-dependent complex network of immune escape mechanisms beyond HLA-I/APM components and T cell infiltration in this tumor entity.
\end{abstract}


Keywords: oral squamous cell carcinoma; HLA class I; antigen processing machinery; immune cell infiltration; immune escape; prognosis

\section{Introduction}

As one of the eight "hallmarks of cancer", the interaction between immune- and tumor cells plays an integral role in controlling the initiation and progression of malignant diseases. A growing body of evidence of changes in the expression of immune modulatory molecules on tumor cells and on cells of the tumor microenvironment (TME) as well as of alterations in the immune contexture, in particular the nature, composition, density, localization, and function of immune cell subpopulations, soluble and physical factors, continuously leads to a better understanding of the tumor immune surveillance and immune escape [1]. The characterization of these mechanisms will give insights into the development of innate and acquired resistances to immunotherapies [2,3], which is crucial for improving the efficacy of immunotherapies for the treatment of cancer patients $[4,5]$.

In murine experimental models as well as in human malignant tumors various immune escape strategies resulting in $\mathrm{T}$ cell tolerance and loss of $\mathrm{T}$ cell recognition have been described. These include (i) lack or downregulation of tumor antigen expression, (ii) loss or reduced expression of HLA-I surface molecules due to impaired expression of APM components, (iii) increased expression of immune suppressive molecules, e.g. the programmed death-like receptor ligand 1 (PD-L1) and the non-classical HLA-G and HLA-E antigens, (iv) downregulation of the interferon (IFN) signal pathways, (v) activation of oncogenic pathways and (vi) alterations in the expression of inflammatory cytokines, metabolites and $\mathrm{pH}$ as well as (vii) transcription factors [6-9]. Despite a loss of heterozygosity and somatic mutations of HLA-I antigens have been detected in different tumor entities [10-12], their frequency is relatively rare suggesting that the impaired HLA-I surface expression of tumors is mainly due to a deregulation of HLA-I APM components, such as the transporter associated with antigen processing (TAP) subunits and low molecular weight proteins (LMPs), mediated by epigenetic, transcriptional and/or post-transcriptional control [9,13]. This can occur at each step of the complex HLA-I APM and affect the anti-tumoral T cell responses [14-17]. Furthermore, an immune suppressive TME mediated by e.g. cellular and soluble components as well as by the interaction of the intra- and peri-tumoral immune cells negatively interferes with the immune control and could influence the prognosis of tumor patients and their response to (immuno)therapies [14,18].

Despite recent treatment advances, oral squamous cell cancer (OSCC) is with 700.000 new cases and 380.000 deaths worldwide [19] still one of the leading causes of cancer worldwide with an overall poor prognosis [20,21]. In industrialized countries, it is mainly attributed to smoking and alcohol abuse and is in about $5 \%$ of cases associated with human papilloma virus (HPV) infection [22]. Early disease is treated by either surgery or radiotherapy, while for recurrent/metastatic disease palliative chemotherapy is currently the standard of care [23]. Despite advances in cytotoxic therapies and surgical intervention, the prognosis of patients is still limited with only little improvement of their outcome over the last decades [24]. Cancer immunotherapies, in particular immune checkpoint inhibitors (CPI), have been shown to increase the overall survival (OS) of OSCC patients, which led to the FDA approval of the anti-PD-L1 antibody Nivolumab for their treatment $[25,26]$. Despite these promising results, only transient responses or durable responses to only a limited number of patients are generated, while the majority of OSCC patients progress and die of their disease [27]. Thus, there is an urgent need to identify prognostic and predictive markers and novel therapeutic targets. Emerging evidence of an enriched immune landscape with key immunological features and prognostic relevance in OSCC exists, which was confirmed by in silico analyses of TCGA data [28]. In colorectal cancer (CRC) the quantification of adaptive immune cells composed of $\mathrm{CD}^{+} \mathrm{T}$ lymphocytes with a cytotoxic (CD8) and memory (CD45RO) phenotype located at the invasive margin (IM) and tumor center (TC) called "immunoscore" was established as a risk predictor more powerful than TNM and histologic grading in this context. The use of the immunoscore as a 
consensus biomarker [29,30] and as a tool to distinguish between responders and non-responders to CPI therapies [31] might be also useful for OSCC patients.

Concerning HPV- OSCC, our group recently proposed a more sophisticated immunoscore termed "cumulative suppression index" (CSI). By evaluating the density and geography of the TME, in particular the spatial distance of $\mathrm{CD}^{+} / \mathrm{CD}^{+} \mathrm{T}$ cells to $\mathrm{CD}^{+} / \mathrm{CD} 8 / \mathrm{FoxP} 3^{+} \mathrm{T}$ cells, the CSI was of prognostic relevance in large tumors independent of well-established prognostic factors and it had a strong effect on the patient's OS [32]. However, OSCC cells have developed different strategies to counteract immune recognition involving both intrinsic cancer related factors and extrinsic mechanisms, like an immune suppressive TME and the downregulated expression of HLA-I APM surface antigen components recognized by tumor-specific $\mathrm{T}$ cells due to the reduced expression of HLA-I APM components [6]. Mapping these escape mechanisms might help to develop strategies to overcome this tolerance [33]. Therefore, the expression of HLA-I heavy chain (HC), $\beta_{2}-\mathrm{m}$ and four distinct APM components (TAP1, TAP2, LMP2 and LMP10) was determined in $160 \mathrm{HPV}$ - OSCC using immunohistochemistry (IHC) and qPCR, respectively. These data were correlated to tumor specific characteristics, the composition of the TME and the patients' outcome and were further validated by evaluation of corresponding data of The Cancer Genome Atlas (TCGA) from 103 HPV-HNSCC cases.

\section{Results}

\subsection{Correlation of clinicopathological data with the overall survival of OSCC patients}

A comprehensive overview of the clinicopathologic data and the OS of the $160 \mathrm{HPV}$ - OSCC patients included in this study is summarized in Table 1A. Gender and age had no influence on the survival, while the $\mathrm{T}$ stage and the presence of metastases significantly correlated with a poor survival. These data were confirmed by TCGA cohort analysis of $103 \mathrm{HPV}$ - HNC, where no prognostic differences concerning gender and age of the patients were reported either. Instead, a better survival was found for HPV- HNC patients at low N stage. Unexpected, but in line with other studies, the WHO tumor grading had no prognostic significance in both collectives (Table 1A) [34].

As demonstrated in Table 1B, locally extended tumors received radiation therapy, while adjuvant standard chemotherapy was administered in all cases with tumor dissemination irrespective of tumor size, but in particular in patients with a T1/2 tumor.

Table 1. Patient specific characteristics.

A: Clinicopathologic data and overall survival of $160 \mathrm{HPV}$ - OSCC patients.

\begin{tabular}{|c|c|c|c|}
\hline \multirow{3}{*}{ category } & \multirow{3}{*}{ no. of cases } & \multicolumn{2}{|c|}{ overall survival (OS): all tumors } \\
\hline & & univariable analysis & multivariable analysis* \\
\hline & & RR; p-value & RR; p-value \\
\hline \multicolumn{4}{|l|}{ gender } \\
\hline men & 124 & & \\
\hline women & 36 & $0.79 ; \mathrm{p}=0.4$ & $0.87 ; \mathrm{p}=0.64$ \\
\hline \multicolumn{4}{|l|}{ age (years) } \\
\hline$\leq 60$ & 91 & & \\
\hline$>60$ & 69 & $1.17 ; \mathrm{p}=0.49$ & $1.29 ; \mathrm{p}=0.26$ \\
\hline \multicolumn{4}{|l|}{ T stage } \\
\hline I & 32 & & \\
\hline II & 49 & $2.54 ; p=0.025$ & $2.75 ; p=0.02$ \\
\hline III & 24 & $3.04 ; \mathrm{p}=0.018$ & $3.10 ; \mathrm{p}=0.028$ \\
\hline IV & 55 & $6.99 ; \mathrm{p}<0.0001$ & $6.92 ; \mathrm{p}<0.0001$ \\
\hline \multicolumn{4}{|l|}{ N stage } \\
\hline No & 71 & & \\
\hline N1-3 & 89 & $2.22 ; \mathrm{p}=0.001$ & $1.26 ; p=0.4$ \\
\hline \multicolumn{4}{|l|}{ M stage } \\
\hline Mo & 154 & & \\
\hline M1 & 6 & $2.41 ; p=0.057$ & 3.16; $\mathrm{p}=0.017$ \\
\hline \multicolumn{4}{|l|}{ grading } \\
\hline 1 & 18 & & \\
\hline
\end{tabular}




\begin{tabular}{cccc}
\hline 2 & 107 & $0.96 ; \mathrm{p}=0.92$ & $0.65 ; \mathrm{p}=0.24$ \\
3 & 35 & $0.85 ; \mathrm{p}=0.69$ & $0.58 ; \mathrm{p}=0.2$ \\
\hline
\end{tabular}

${ }^{*}$ Cox proportional hazards regression: adjusted for $\mathrm{T}, \mathrm{N}$ stage and grading; RR, relative risk. Statistically significant data is marked in bold.

B: Frequency and intensity of adjuvant therapy.

\begin{tabular}{ccccc}
\hline $\begin{array}{c}\text { UICC } \\
\text { T } \\
\text { stage }\end{array}$ & $\begin{array}{c}\text { number of } \\
\text { cases }\end{array}$ & $\begin{array}{c}\text { adjuvant radiation therapy } \\
\text { received }\end{array}$ & $\begin{array}{c}\text { median dosage } \\
\text { (gy) }\end{array}$ & $\begin{array}{c}\text { adjuvant standard chemotherapy } \\
\text { received }\end{array}$ \\
\hline I & 32 & $14(44 \%)$ & 50,2 & $24(75 \%)$ \\
II & 49 & $26(53 \%)$ & 50,0 & $12(25 \%)$ \\
III & 24 & $17(71 \%)$ & 64,0 & $9(38 \%)$ \\
IV & 55 & $40(73 \%)$ & 64,0 & $31(56 \%)$ \\
\hline
\end{tabular}

The frequency of radiation therapy (\%) including the median dosage as well as the frequency of standard chemotherapy (\%) of patients in different $\mathrm{T}$ stages is given.

\subsection{HLA-I/APM component expression in OSCC tumors and its correlation to tumor staging}

In order to determine the expression levels of HLA-I/APM components in OSCC, protein expression of HLA-I HC, $\beta_{2}-\mathrm{m}$ and the APM molecules TAP1, TAP2, LMP2 and LMP10 were analyzed by IHC of formalin-fixed, paraffin embedded (FFPE) tumor lesions [35]. IHC staining revealed at least slightly reduced, but heterogeneous cytoplasmic, membranous and / or nuclear expression levels depending on HLA-I and APM components analyzed when compared to the surrounding non-malignant cells (data not shown).

Based on the HLA-I (HC/ $\left./ \beta_{2}-\mathrm{m}\right)$ and APM (TAP, LMP) component expression pattern in the FFPE lesions, OSCC were categorized into four distinct HLA/APM phenotypes (phenotype I-IV, see Materials and Methods). In short, while phenotype I expressed high levels of both the HLA-I HC/ $\beta_{2-}$ $\mathrm{m}$ and APM components (HLA- $\mathrm{Ih}^{\text {high}} / \mathrm{APM}^{\text {high }}$ ), phenotype II displayed a concordant low expression pattern of both components (HLA-I low/APM ${ }^{\text {low }}$ ). Phenotype III expressed discordant levels of HLA-I $\mathrm{HC} / \beta_{2}-\mathrm{m}$ and high levels of APM components (HLA-Idiscordant high/ow/APM $\left.{ }^{\text {high}}\right)$. Phenotype IV with discordant HLA-I and low APM expression was omitted from further analyses due to the low group size (Table 2A). It is noteworthy that the three HLA/APM phenotypes were uniformly distributed over the different $\mathrm{T}$ stages (Table 2B). As the HC10 antibody only recognizes the HLA-I HC, corresponding fresh frozen OSCC tissues from five FFPE OSCC lesions with phenotype I and five OSCC lesions with phenotype II were stained with the HLA-A/B/C antibody W6/32 recognizing the functional trimeric HLA-I HC/ $\beta_{2}-\mathrm{m}$ and peptide complex [36]. In these selected cases, the expression levels of HLA-I HC together with $\beta_{2}$-m staining were comparable to those obtained by employing the $\mathrm{W} 6 / 32$ monoclonal antibody $(\mathrm{mAb})$. These findings suggest expression of the functional trimeric HLA-I complex at least in the OSCC cases analyzed (Figure 1, Supplementary Table 1). As a further control, HLA-I HC and $\mathrm{B}_{2}-\mathrm{m}$ mRNA expression was analyzed in a subset of OSCC specimens also demonstrating concordant expression profiles when compared to the protein data (data not shown). 
Table 2. HLA-I and APM protein expression patterns in OSCC lesions.

A: Classification of OSCC lesions according to the HLA-I/APM expression.

\begin{tabular}{|c|c|c|c|c|c|c|c|c|}
\hline HLA-I/APM phenotype & $\begin{array}{c}\text { patients } \\
(\mathrm{n}=160)\end{array}$ & $\mathrm{HC}$ & $\beta_{2-m}$ & TAP1 & TAP2 & LMP2 & LMP10 & $\begin{array}{c}\text { expression } \\
\text { pattern }\end{array}$ \\
\hline I [HLA-I ${ }^{\text {high }}-$ APM $\left.^{\text {high }}\right]$ & $57(36 \%)$ & + & + & + & + & + & + & \multirow{2}{*}{$\begin{array}{l}\text { concordant } \\
\text { HLA-I/APM } \\
\text { expression }\end{array}$} \\
\hline II $\left[\right.$ HLA-Ilow - APM $\left.^{\text {low }}\right]$ & $12(8 \%)$ & - & - & - & - & - & - & \\
\hline \multirow{2}{*}{$\begin{array}{c}\text { III [HLA-Idiscordant high/low } \\
\left.- \text { APM }^{\text {high }}\right]\end{array}$} & $89(56 \%)$ & + & - & \multirow{2}{*}{+} & \multirow{2}{*}{+} & \multirow{2}{*}{+} & \multirow{2}{*}{+} & \multirow{4}{*}{$\begin{array}{l}\text { discordant } \\
\text { HLA-I/APM } \\
\text { expression }\end{array}$} \\
\hline & & - & + & & & & & \\
\hline \multirow{2}{*}{$\begin{array}{c}\text { IV [HLA-Idiscordant high/low } \\
\left.- \text { APM }^{\text {low }}\right]^{*}\end{array}$} & $2(<1 \%)$ & + & - & \multirow[b]{2}{*}{ - } & \multirow{2}{*}{-} & \multirow{2}{*}{ - } & \multirow{2}{*}{ - } & \\
\hline & & - & + & & & & & \\
\hline
\end{tabular}

* omitted from further analyses due to limited group size. A discordant HLA-I HC and $\beta_{2}$-m expression is marked as high/low.

B: Distribution of T stages across HLA-I/APM phenotypes.

\begin{tabular}{cccccc}
\hline $\begin{array}{c}\text { HLA-I/APM } \\
\text { phenotype }\end{array}$ & T1 & T2 & T3 & T4 & all Ts \\
\hline $\begin{array}{c}\text { I [HLA-Ihigh/ } \\
\text { APMhigh] }\end{array}$ & $16(50 \%)$ & $15(31 \%)$ & $12(50 \%)$ & $14(26 \%)$ & $57(36 \%)$ \\
\hline $\begin{array}{c}\text { II }\left[\mathrm{HLA}-I^{\text {low }}\right. \\
\text { APM }\end{array}$ & $3(9 \%)$ & $2(4 \%)$ & $3(13 \%)$ & $4(7 \%)$ & $12(8 \%)$ \\
\hline $\begin{array}{c}\text { III }\left[\mathrm{HLA}-I^{\text {discordant }}\right. \\
\text { high/low/APM }\end{array}$ & $12(38 \%)$ & $31(63 \%)$ & $9(37 \%)$ & $37(67 \%)$ & $89(55 \%)$ \\
\hline $\begin{array}{c}\text { IV [HLA-I } \\
\text { high/low/APM }\end{array}$ & $1(3 \%)$ & $1(2 \%)$ & - & - & $2(1 \%)$ \\
\hline
\end{tabular}

* omitted from further analyses due to limited group size. A discordant HLA-I HC and $\beta_{2}-\mathrm{m}$ expression is marked as high/low. 
Figure 1. Representative high and low staining patterns of OSCC lesions for HLA-I HC, $\beta_{2}-\mathrm{m}$ and the trimeric HLA-I complex.

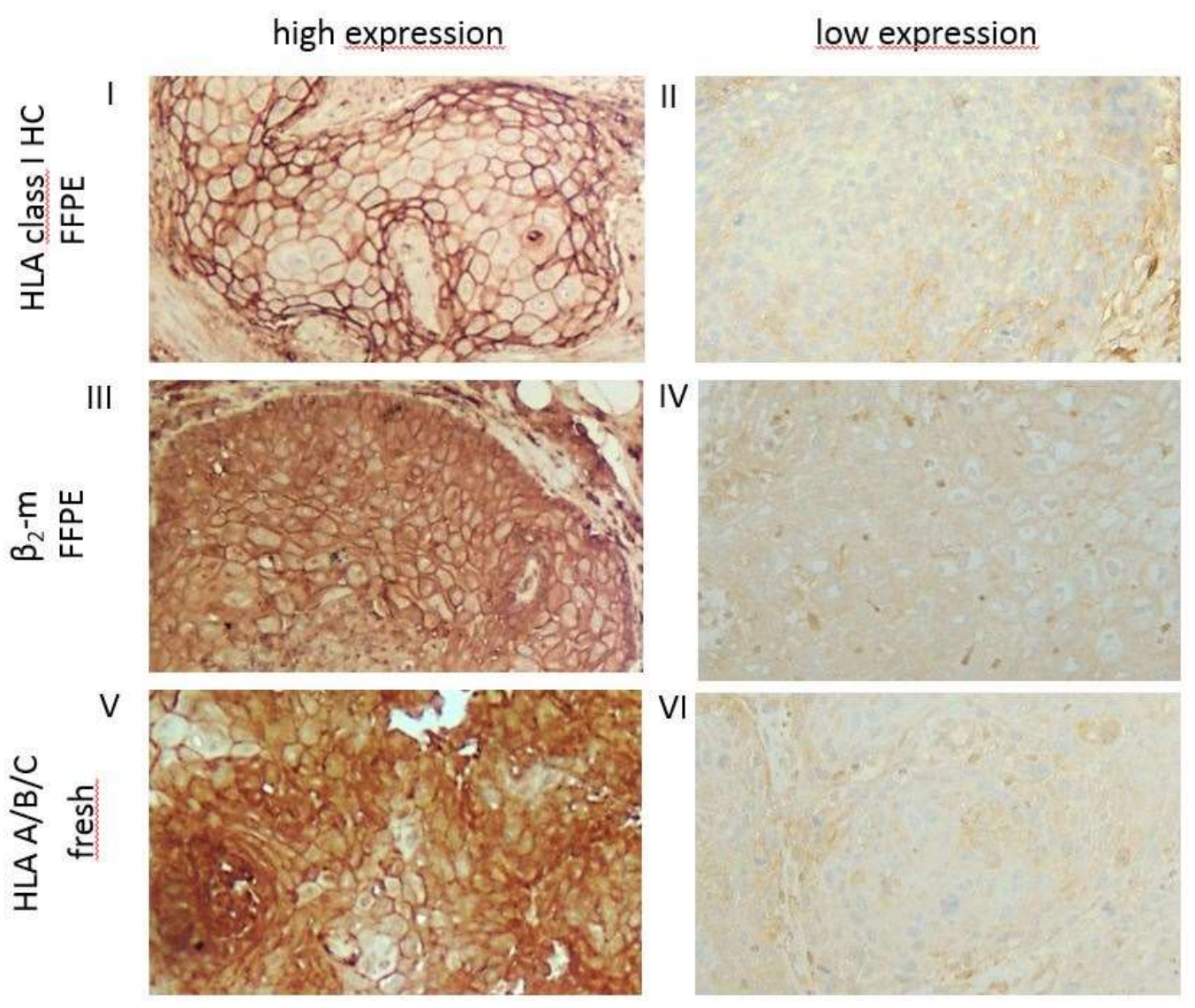

Representative immunohistochemical analyses using antibodies directed against HLA class I HC (FFPE, I, II), $\beta_{2}$-m (FFPE III, IV) and the trimeric HLA class I A/B/C complex (W6/32; fresh frozen, $\mathrm{V}, \mathrm{VI})$. Representative cases with a high (I, III) or low (II, IV) cytoplasmic and membranous expression of HLA class I HC and $\beta_{2}-\mathrm{m}$ in FFPE samples are shown and compared to a staining of the trimeric HLA class I complex (V, VI) on fresh frozen tissues. Each image was done at a 200x resolution.

\subsection{Impact of tumoral HLA-I/APM expression on the intra-tumoral immune cell cross talk}

To elucidate the impact of OSCC HLA-I/APM expression on the immune cell repertoire, the HLA-I HC and/or $\beta_{2}$-m expression data were correlated to the frequency and the composition of intratumoral $\mathrm{T}$ cell subpopulations recently acquired by multispectral imaging within the same sample collective [32] and to the UICC tumor stages. As demonstrated in Figure 2 within all T stages, the density of $\mathrm{CD} 8^{+} \mathrm{T}$ cells was significantly higher in the HLA-I HC/ $/ 32-\mathrm{m}^{\text {high/high }}$ group than in the two other groups.

Figure 2. Intra-tumoral density of T cell subpopulations across the HLA-I/APM phenotypes I-III in correlation to the T stage. 


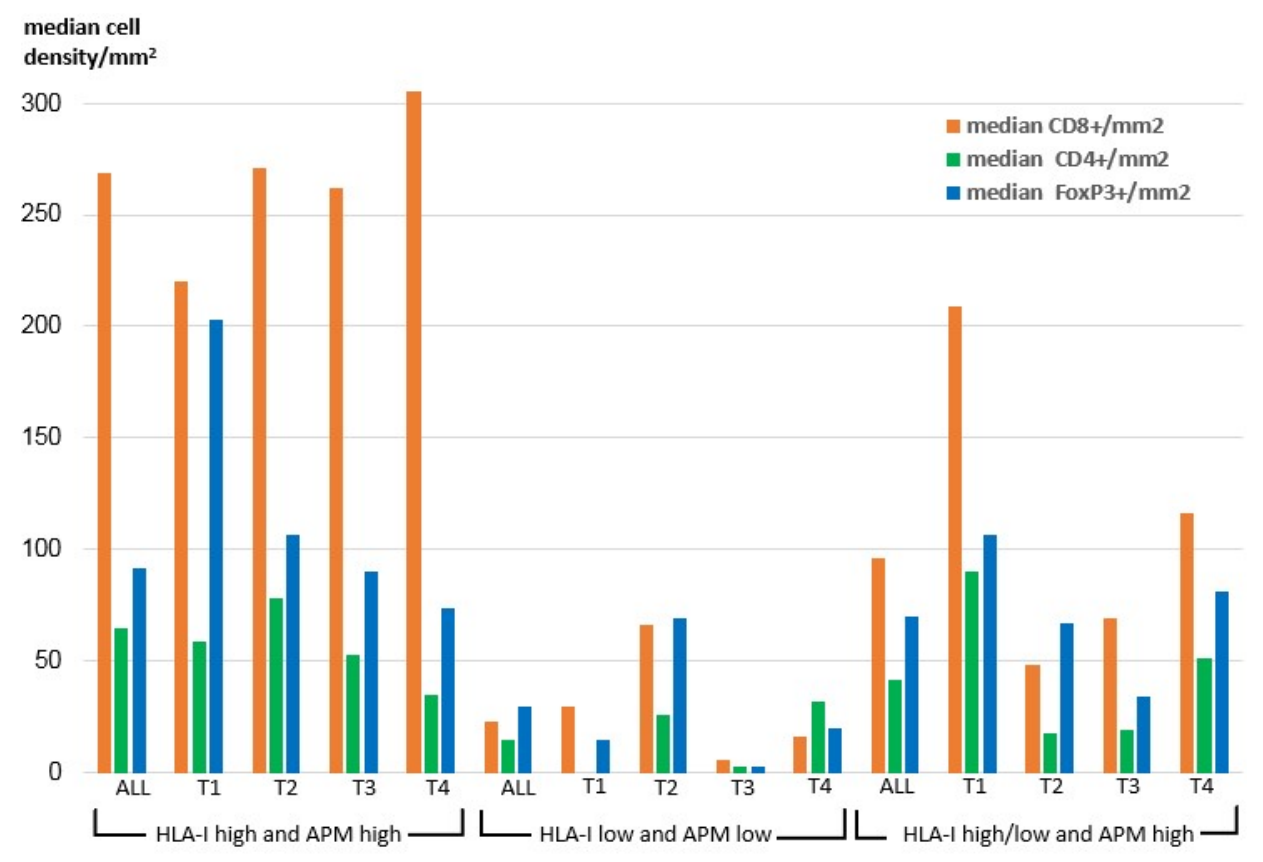

Distribution of the median cell density of the $\mathrm{T}$ cell subpopulations across the HLA-I/APM phenotypes in correlation to the T stage.

In detail, the intensity of tumoral HLA-I $\mathrm{HC} / \beta_{2}-\mathrm{m}$ surface expression correlated highly significant positively with the density of intra-tumoral $C D 8^{+} T$ cells $(\mathrm{p}=0.008$ resp. 0.003), but negatively with the number of $\mathrm{CD}^{+} \mathrm{T}$ cells adjacent to FoxP3 $3^{+}$cells within a radius of $30 \mu \mathrm{m}(\mathrm{p}=0.009$ resp. 0.007) (Table 3A). Furthermore, a positive correlation between the expression of LMP2 and the density of $\mathrm{CD}^{+} \mathrm{T}$ cells was detected $(\mathrm{p}=0.003)$. In this context, it is noteworthy that we found a positive correlation of the intra-tumoral JAK1 expression with the intra-tumoral density of CD8 $8^{+} \mathrm{T}$ cells $(p=0.024)$, while no correlation of JAK1 expression with the HLA-I HC, $\beta_{2}-\mathrm{m}$ and APM component expression was found (data not shown).

In silico analyses of TCGA data were in line with these findings as the mRNA expression levels of the major HLA-I/APM genes positively correlated with the quantity of the T cell infiltrate demonstrating a significant association of CD8A with the HLA-I HC, $\beta_{2}-\mathrm{m}$, TAP1, TAP2, LMP2 and LMP10 (Table 3B, Suppl. Figure 1).

Table 3. Interrelationship of intra-tumoral HLA-I, APM component and JAK1 expression with the intra-tumoral $\mathrm{T}$ cell infiltrate.

A: Bivariable correlation of the expression of the HLA-I HC, $\beta_{2}-\mathrm{m}$, APM components and JAK1 with the intra-tumoral $\mathrm{T}$ cell infiltrate.

\begin{tabular}{|c|c|c|c|c|c|c|c|c|}
\hline & & HLA-I HC & $\beta_{2-m}$ & TAP1 & TAP2 & LMP2 & LMP10 & JAK1 \\
\hline $\begin{array}{l}\text { Intra-tumoral } \mathrm{T} \\
\text { cell infiltrate }\end{array}$ & $\mathbf{N}$ & $\begin{array}{c}\mathrm{rs}_{\mathrm{s}} \\
\text { (p-value) }\end{array}$ & $\begin{array}{c}\mathrm{rs}_{\mathrm{s}} \\
\text { (p-value) }\end{array}$ & $\begin{array}{c}\mathrm{rs}_{\mathrm{s}} \\
\text { (p-value) }\end{array}$ & $\begin{array}{c}\text { rs } \\
\text { (p-value) }\end{array}$ & $\begin{array}{c}\mathrm{rs}_{\mathrm{s}} \\
\text { (p-value) }\end{array}$ & $\begin{array}{c}\mathrm{rs}_{\mathrm{s}} \\
\text { (p-value) }\end{array}$ & $\begin{array}{c}\mathrm{rs}_{\mathrm{s}} \\
\text { (p-value) }\end{array}$ \\
\hline $\mathrm{CD}^{+} / \mathrm{mm}^{2}$ & 108 & $\begin{array}{l}0.150 \\
(0.12) \\
\end{array}$ & $\begin{array}{c}0.216 \\
(0.03)^{*}\end{array}$ & $\begin{array}{r}-0.142 \\
(0.14) \\
\end{array}$ & $\begin{array}{c}0.168 \\
(0.08)^{*}\end{array}$ & $\begin{array}{c}0.229 \\
(0.017)^{*}\end{array}$ & $\begin{array}{l}0.120 \\
(0.22) \\
\end{array}$ & $\begin{array}{l}0.027 \\
(0.78) \\
\end{array}$ \\
\hline $\mathrm{CD}^{+} / \mathrm{mm}^{2}$ & 119 & $\begin{array}{c}0.242 \\
(0.008)^{* *} \\
\end{array}$ & $\begin{array}{c}0.272 \\
(0.003)^{* *} \\
\end{array}$ & $\begin{array}{l}-0.172 \\
(0.08)^{*} \\
\end{array}$ & $\begin{array}{l}0.118 \\
(0.20) \\
\end{array}$ & $\begin{array}{c}0.270 \\
(0.003)^{* *} \\
\end{array}$ & $\begin{array}{l}0.095 \\
(0.30) \\
\end{array}$ & $\begin{array}{c}0.178 \\
(0.06)^{*}\end{array}$ \\
\hline $\mathrm{FoxP}^{+} / \mathrm{mm}^{2}$ & 119 & $\begin{array}{c}0.190 \\
(0.04)^{*}\end{array}$ & $\begin{array}{c}0.246 \\
(0.007)^{* *} \\
\end{array}$ & $\begin{array}{l}-0.239 \\
(0.01)^{*}\end{array}$ & $\begin{array}{c}0.198 \\
(0.03)^{*}\end{array}$ & $\begin{array}{l}0.146 \\
(0.11) \\
\end{array}$ & $\begin{array}{l}0.012 \\
(0.90) \\
\end{array}$ & $\begin{array}{l}0.115 \\
(0.24) \\
\end{array}$ \\
\hline $\begin{array}{l}\mathrm{CD}^{+} \text {to FoxP3 } \\
\text { within } 30 \mu \mathrm{m}\end{array}$ & 119 & $\begin{array}{c}-0.238 \\
(0.009)^{* *}\end{array}$ & $\begin{array}{c}-0.248 \\
(0.007)^{* *}\end{array}$ & $\begin{array}{c}-0.034 \\
(0.73)\end{array}$ & $\begin{array}{r}-0.043 \\
(0.64)\end{array}$ & $\begin{array}{c}-0.223 \\
(0.015)^{*}\end{array}$ & $\begin{array}{r}-0.024 \\
(0.79) \\
\end{array}$ & $\begin{array}{l}-0.097 \\
(0.318)\end{array}$ \\
\hline
\end{tabular}

Spearman's Rho test: $\mathrm{rs}_{\mathrm{s}}$-correlation coefficient; statistically significant data are marked in bold. * denotes $\mathrm{p}<0.05$; ${ }^{* *}$ denotes $\mathrm{p}<0.01$. 
B: Correlation of the mRNA expression of HLA-I/APM components with $T$ cell markers using TCGA data from HPV- HNC patients.

\begin{tabular}{ccccccc}
\hline & HLA-A & $\beta_{2}-\mathrm{m}$ & TAP1 & TAP2 & LMP2 & LMP10 \\
\hline \multirow{2}{*}{ CD4 } & $\mathrm{r}_{\mathrm{s}}=0.351$ & $\mathrm{r}_{\mathrm{s}}=0.458$ & $\mathrm{r}_{\mathrm{s}}=0.394$ & $\mathrm{r}_{\mathrm{s}}=0.372$ & $\mathrm{r}_{\mathrm{s}}=0.328$ & $\mathrm{r}_{\mathrm{s}}=0.474$ \\
& $\left(\mathrm{p}=2.3 \mathrm{e}^{-3}\right)$ & $\left(\mathrm{p}=4.6 \mathrm{e}^{-5}\right)$ & $\left(\mathrm{p}=5.6 \mathrm{e}^{-4}\right)$ & $\left(\mathrm{p}=1.2 \mathrm{e}^{-3}\right)$ & $\left(\mathrm{p}=4.6 \mathrm{e}^{-3}\right)$ & $\left(\mathrm{p}=2.3 \mathrm{e}^{-5}\right)$ \\
\hline \multirow{2}{*}{ CD8A } & $\mathrm{r}_{\mathrm{s}}=0.506$ & $\mathrm{r}_{\mathrm{s}}=0.698$ & $\mathrm{r}_{\mathrm{s}}=0.699$ & $\mathrm{r}_{\mathrm{s}}=0.642$ & $\mathrm{r}_{\mathrm{s}}=0.653$ & $\mathrm{r}_{\mathrm{s}}=0.671$ \\
& $\left(\mathrm{p}=5.0 \mathrm{e}^{-6}\right)$ & $\left(\mathrm{p}=7.0 \mathrm{e}^{-12}\right)$ & $\left(\mathrm{p}=1.5 \mathrm{e}^{-11}\right)$ & $\left(\mathrm{p}=9.4 \mathrm{e}^{-10}\right)$ & $\left(\mathrm{p}=3.7 \mathrm{e}^{-10}\right)$ & $\left(\mathrm{p}=7.9 \mathrm{e}^{-11}\right)$ \\
\hline \multirow{2}{*}{ FoxP3 } & $\mathrm{r}_{\mathrm{s}}=0.347$ & $\mathrm{r}_{\mathrm{s}}=0.460$ & $\mathrm{r}_{\mathrm{s}}=0.445$ & $\mathrm{r}_{\mathrm{s}}=0.45$ & $\mathrm{r}_{\mathrm{s}}=0.342$ & $\left(\mathrm{p}=3.1 \mathrm{e}^{-3}\right)$ \\
& $\left(\mathrm{p}=2.7 \mathrm{e}^{-3}\right)$ & $\left(\mathrm{p}=4.2 \mathrm{e}^{-5}\right)$ & $\left(\mathrm{p}=7.9 \mathrm{e}^{-5}\right)$ & $\left(\mathrm{p}=6.4 \mathrm{e}^{-5}\right)$ & $\left(\mathrm{p}=6.0 \mathrm{e}^{-4}\right)$ \\
\hline
\end{tabular}

Spearman's Rho test; rs-correlation coefficient. In silico analyses of tumor samples from $103 \mathrm{HPV}^{-} \mathrm{HNC}^{-6}$

patients obtained from the TCGA data bank presented as $r_{s}$.

To further evaluate the probability of the induction of HLA-I/APM expression by T cell secreted IFN- $\gamma$, basal and IFN- $\gamma$-regulated transcription and protein expression levels in three human HNSCC cell lines were determined using qPCR, Western blot analyses and flow cytometry. In this approach constitutive, but rather low mRNA levels of HLA-I APM components were detected in all three analyzed cell lines, which was even more pronounced at the protein level and accompanied by low HLA-I surface expression levels. IFN- $\gamma$ treatment upregulated both HLA-I and APM mRNA and protein expression (Supplementary Figure 2A) suggesting a direct link between HLA-I/APM upregulation and $\mathrm{T}$ cell induced IFN $-\gamma$ secretion.

\subsection{Impact of OSCC HLA-I/APM expression on the outcome of the patients}

To elucidate the clinical impact of the different HLA-I/APM phenotypes of OSCC, the HLA-I APM expression results were set in relation to the OS of the patients using uni- and multivariable Cox proportional hazard regression and Kaplan-Meier curves. Here, an increase in HLA-I HC and $\beta_{2}$-m expression negatively affected the OS independent of the tumor size. We next analyzed whether this effect was influenced by the $\mathrm{T}$ stage or, more specifically, the tumor mass. When considering T1/2 vs. T3/4 tumors, no significant effect was found (Table $4 \mathrm{~A}$ ). In contrast, a significantly worse OS and 4.4-fold higher risk of death $(\mathrm{p}=0.003$; multivariable Cox regression, adjusting for UICC N-stage and grading) was detected in phenotype I [HLA-I ${ }^{\text {high }} / \mathrm{APM}^{\mathrm{high}}$ ] in comparison to phenotype III [HLAIdiscordant low/high/ $\mathrm{APM}^{\text {high }}$ ] and to a lesser intent to phenotype II [HLA-I low/APM ${ }^{\text {low }}$ ] by solely focusing on T2 tumors (Figure 3). Based on these data, we assume that the different results of T1 versus T2 tumors were due to the much better OS of patients with $\mathrm{T} 1$ tumors independent of the immune phenotype (Table 1).

In line with these data, in silico analyses employing the XENA database (https://xenabrowser.net/) revealed a reduced OS in HLA-Ihigh/APM ${ }^{\text {high }}$ HNSCC in comparison to HLA-Ilow/APM ${ }^{\text {low }}$ HNSCC lesions. In this study, higher levels of TAP1 expression correlated with a better OS (Table 4B).

Table 4. Correlation of OSCC HLA-I/APM expression, $\mathrm{T}$ stage, intra-tumoral T cell infiltrate and overall survival.

A: Expression of HLA-I/APM components and correlation with T1/2 and T3/4 stage as well as overall survival.

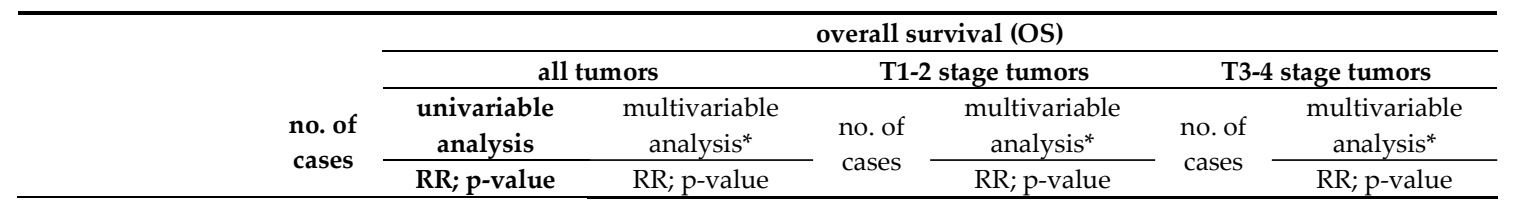




\begin{tabular}{|c|c|c|c|c|c|c|c|}
\hline \multicolumn{8}{|l|}{$\begin{array}{l}\text { HLA-APM } \\
\text { phenotype }\end{array}$} \\
\hline $\begin{array}{c}\text { I [HLA-I } \text { high- }^{\text {higM }} \\
\text { APigh] }\end{array}$ & 57 & \multirow{4}{*}{$\begin{array}{l}\text { I vs. III: } 0.59 ; \\
\quad p=0.63\end{array}$} & \multirow{4}{*}{$\begin{array}{l}\text { I vs. III: } 1.29 ; \\
\quad \mathrm{p}=0.55\end{array}$} & 31 & \multirow{3}{*}{$\begin{array}{l}\text { I vs.III: } 1.86 \text {; } \\
\quad \text { p=0.11 }\end{array}$} & \multicolumn{2}{|l|}{26} \\
\hline $\begin{array}{l}\text { II [HLA-Ilow- } \\
\text { APM }^{\text {low] }}\end{array}$ & 12 & & & 5 & & 7 & $\begin{array}{l}\text { I vs. III: } 1.08 ; \\
\quad p=0.82\end{array}$ \\
\hline $\begin{array}{c}\text { III [HLA-Ihigh/low_ } \\
\text { APM }^{\text {high] }}\end{array}$ & 89 & & & 43 & & 46 & \\
\hline $\begin{array}{c}\text { IV [HLA-Ihigh/low_- } \\
\left.\text { APM }^{\text {low }}\right]\end{array}$ & 2 & & & 2 & & 0 & \\
\hline \multicolumn{8}{|l|}{ HLA-I HC } \\
\hline IRS 0-3 & 64 & & & 34 & & 30 & \\
\hline IRS 4-12 & 96 & $1.53 ; p=0.07$ & $1.52 ; p=0.08$ & 51 & $1.86 ; p=0.11$ & 49 & $1.25 ; \mathrm{p}=0.47$ \\
\hline \multicolumn{8}{|l|}{ membranous } \\
\hline IRS 0-4 & 100 & & & 51 & & 49 & \\
\hline IRS 6-12 & 60 & $1.13 ; p=0.59$ & $1.04 ; p=0.86$ & 30 & $1.85 ; p=0.10$ & 30 & $0.72 ; p=0.26$ \\
\hline \multicolumn{8}{|l|}{$\beta_{2}-m$} \\
\hline \multicolumn{8}{|l|}{ cytoplasmic } \\
\hline IRS 0-3 & 48 & & & 27 & & 21 & \\
\hline IRS 4-12 & 112 & $1.80 ; p=0.026$ & $1.66 ; p=0.056$ & 54 & $2.29 ; p=0.061$ & 58 & $1.41 ; \mathrm{p}=0.31$ \\
\hline \multicolumn{8}{|l|}{ membranous } \\
\hline IRS 0-4 & 105 & & & 56 & & 53 & \\
\hline IRS 6-12 & 55 & $0.97 ; p=0.9$ & $0.93 ; p=0.75$ & 25 & $1.53 ; p=0.28$ & 26 & $0.8 ; \mathrm{p}=0.49$ \\
\hline \multicolumn{8}{|l|}{ TAP1 } \\
\hline \multicolumn{8}{|l|}{ cytoplasmic } \\
\hline IRS 0-2 & 18 & & & 8 & & 10 & \\
\hline IRS 3-12 & 49 & $0.57 ; p=0.09$ & $0.57 ; p=0.13$ & 25 & $0.89 ; p=0.87$ & 24 & $0.56 ; p=0.20$ \\
\hline \multicolumn{8}{|l|}{ TAP2 } \\
\hline IRS 0-4 & 49 & & & 26 & & 23 & \\
\hline IRS 6-12 & 111 & $1.31 ; p=0.27$ & $1.42 ; \mathrm{p}=0.17$ & 55 & $1.02 ; \mathrm{p}=0.96$ & 56 & $2.35 ; \mathrm{p}=0.02$ \\
\hline \multicolumn{8}{|l|}{$L M P 2$} \\
\hline IRS 0-4 & 105 & & & 53 & & 52 & \\
\hline $\begin{array}{l}\text { IRS 6-12 } \\
\text { nuclear }\end{array}$ & 55 & $0.99 ; p=0.96$ & $0.99 ; p=0.99$ & 28 & $1.02 ; p=0.96$ & 27 & $1.06 ; \mathrm{p}=0.84$ \\
\hline IRS 0-4 & 69 & & & 34 & & 35 & \\
\hline IRS 6-12 & 91 & $1.52 ; p=0.07$ & $1.56 ; \mathrm{p}=0.054$ & 47 & $2.4 ; p=0.04$ & 44 & $1.44 ; \mathrm{p}=0.2$ \\
\hline \multicolumn{8}{|l|}{$\begin{array}{c}\text { LMP10 } \\
\text { cytoplasmic }\end{array}$} \\
\hline IRS 0-2 & 32 & & & 22 & & 10 & \\
\hline $\begin{array}{c}\text { IRS 3-12 } \\
\text { nuclear }\end{array}$ & 128 & $1.54 ; p=0.15$ & $1.27 ; p=0.43$ & 59 & $1.34 ; p=0.5$ & 69 & $1.33 ; \mathrm{p}=0.51$ \\
\hline IRS 0-4 & 21 & & & 12 & & 9 & \\
\hline IRS 6-12 & 139 & $1.63 ; p=0.18$ & $1.57 ; p=0.21$ & 69 & $1.26 ; p=0.65$ & 70 & $2.1 ; p=0.16$ \\
\hline
\end{tabular}

${ }^{*}$ Cox proportional hazards regression, adjusted for T, N stage and grading; RR, relative risk.

Statistically significant data is marked in bold.

B: Correlation of OS to the HLA-I/APM component expression using TCGA data of $103 \mathrm{HPV}^{-} \mathrm{HNC}^{\mathrm{H}}$ patients.

\begin{tabular}{ccccc}
\hline $\begin{array}{c}\text { high HLA-A, HLA-B or } \boldsymbol{\beta}_{2}-\mathbf{m} \\
\text { (phenotype I) }\end{array}$ & TAP1 & TAP2 & LMP2 & LMP10 \\
\hline HLA-A & $\mathrm{p}=0.028$ & $\mathrm{p}=0.04$ & $\mathrm{p}=0.068$ & $\mathrm{p}=0.131$ \\
\hline HLA-B & $\mathrm{p}=0.479$ & $\mathrm{p}=0.195$ & $\mathrm{p}=0.045$ & $\mathrm{p}=0.077$ \\
\hline $\boldsymbol{\beta}_{2}-\mathrm{m}$ & $\mathrm{p}=0.019$ & $\mathrm{p}=0.067$ & $\mathrm{p}=0.074$ & $\mathrm{p}=0.145$ \\
\hline $\begin{array}{c}\text { low HLA-A, HLA-B or } \beta_{2}-\mathrm{m} \\
\text { (phenotype II) }\end{array}$ & TAP1 & TAP2 & LMP2 & LMP10 \\
\hline HLA-A & $\mathrm{p}=0.679$ & $\mathrm{p}=0.04$ & $\mathrm{p}=0.059$ & $\mathrm{p}=0.557$ \\
\hline
\end{tabular}




\begin{tabular}{ccccc}
\hline HLA-B & $\mathrm{p}=0.884$ & $\mathrm{p}=0.094$ & $\mathrm{p}=0.028$ & $\mathrm{p}=0.624$ \\
\hline$\beta_{2}-\mathbf{m}$ & $\mathrm{p}=0.873$ & $\mathrm{p}=0.058$ & $\mathrm{p}=0.055$ & $\mathrm{p}=0.801$ \\
\hline
\end{tabular}

The expression data of HLA-I and APM components were obtained from the TCGA of 103 HPVOSCC lesions. The mRNA expression patterns of the APM components TAP1, TAP2 and LMP7 within the phenotypes I and II were correlated to the OS of HPV- HNC patients. The red background in phenotype I indicates a lower OS when TAP1, TAP2 and LMP2 genes and HLA-A, HLA-B and $\beta_{2-}$ $\mathrm{m}$ are highly expressed $(\mathrm{p} \leq 0.1)$, while the grey background indicates no significant differences in the phenotype I. Low expression levels of TAP2, LMP2 and HLA in phenotype II were associated with a better OS (green background), while the grey background indicates no significant differences $(p \leq 0.1)$.

Figure 3. Overall survival of OSCC patients depending on HLA-I / APM phenotype.
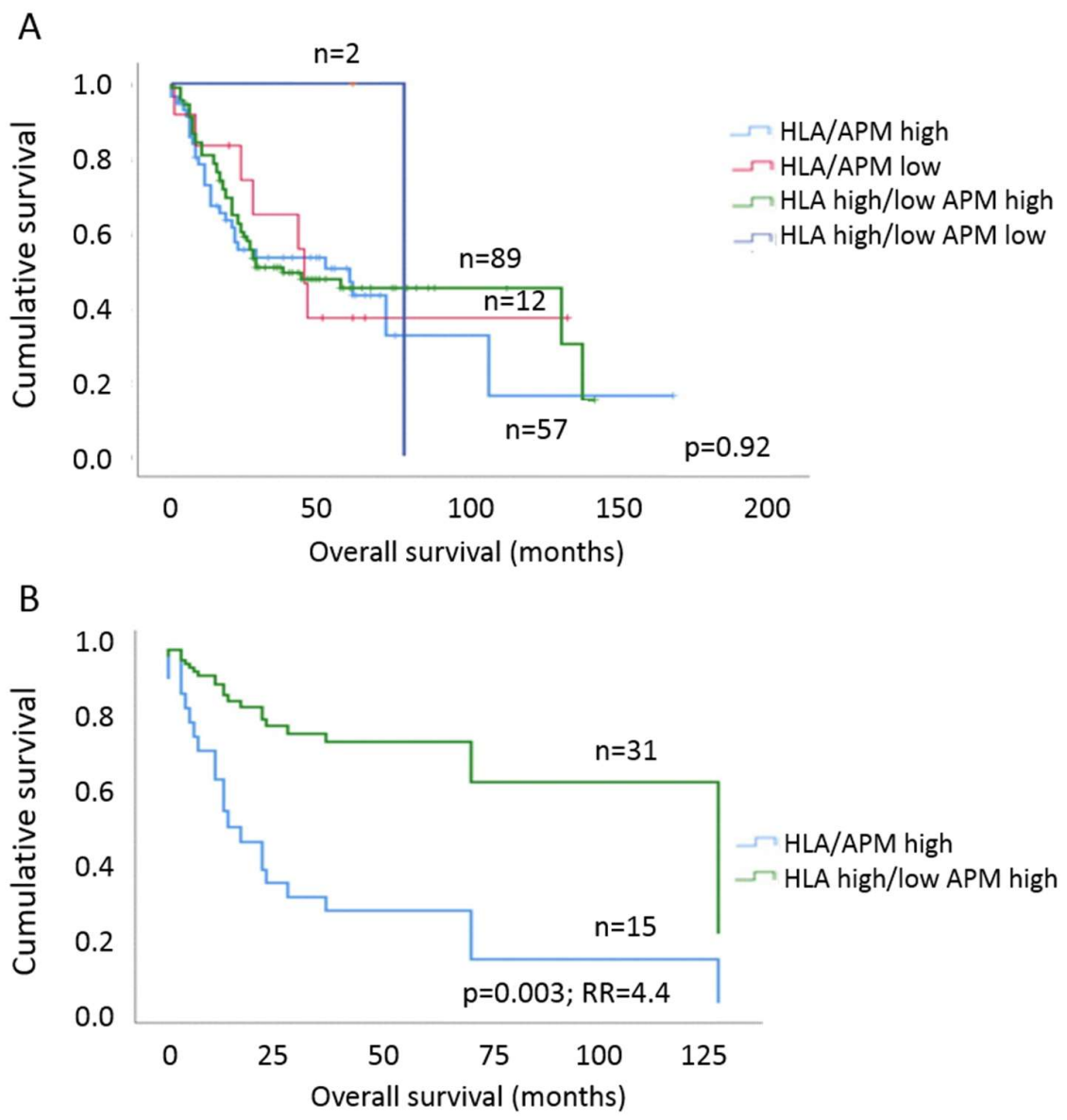

A: Comparison of OS between the four HLA-I/APM phenotypes irrespective of the tumor size. No clear separation of the survival curves was found.

B: OS of OSCC patients when only T2 stage tumors were analyzed. Within this group patients with a HLA$\mathrm{I}^{\text {high} / A P M}{ }^{\text {high }}$ phenotype had a 4.4-fold higher relative risk of death due to OSCC when compared to patients with HLA-I discordant high/low/APM ${ }^{\text {high }}$ phenotype. Multivariable Cox regression adjusting for UICC N stage as well as grading.

\section{Discussion}

It has become evident that an altered expression pattern of HLA-I antigens and HLA-I APM components in tumors represents an important immune escape mechanism from CTL-mediated 
elimination in distinct tumor types and is frequently associated with a poor prognosis and resistance to immunotherapy. These changes have been linked to alterations in the TME [37-40]. In HNSCC, an immune suppressive equilibrium has been identified, which is characterized by a low frequency of dysfunctional immune effector cells and an altered expression of immune modulatory molecules of HNSCC cells [41]. In $\mathrm{HPV}^{+} \mathrm{HNSCC}$, the distinct underlying immune escape mechanisms have been well identified [7,42], while there is still a lack of data concerning immune evasion of HPV- OSCC lesions. Yet a growing body of literature suggested that the immune system plays an important role in the carcinogenesis of HNSCC independent of the HPV status. To get more insight into these processes, this study examined the expression and localization of HLA-I and APM components in HPV-OSCC lesions and correlated the expression pattern with the frequency and density of the intratumoral immune cell infiltrate and clinical parameters to identify prognostic markers of OSCC progression and regulatory pathways, which can be potentially useful in the therapeutic setting. Impaired expression of HLA-I APM components is a frequent event in solid tumors when compared to non-malignant cells thereby progressively inhibiting the ability of CD8 ${ }^{+}$CTL to recognize tumor cells [7,38,43-45]. Indeed, in the panel of HPV- OSCC lesions analyzed in this study we detected an impaired HLA-I APM expression in comparison to adjacent non-tumorigenic tissue, which was more prominent for HLA-I HC and $\beta_{2}-\mathrm{m}$ than for the peptide transporters and proteasome subunits. Since this effect significantly varied within our OSCC collective, we classified the tumors into three major phenotypes according to their HLA-I APM component expression (HLA-I ${ }^{\text {high }} /$ APM ${ }^{\text {high, }}$ HLA$I^{\text {low }} / A P M^{\text {low }}$, HLA-Idiscordant high/low/APMigh). The frequency of the three main HLA-I/APM phenotypes ranged from $12 \%$ (HLA $^{\text {low }} / \mathrm{APM}^{\text {low }}$ ) to $56 \%$ (HLA-Idiscordant high/low/APM ${ }^{\text {high }}$ ) as shown in Table 2A. The reason for the impaired HLA-I/APM expression of phenotype II might be structural alterations or epigenetic silencing of both HLA-I and APM components, while in phenotype III, the APM component expression is functional and only the HLA-I expression is reduced or discordant, which might be foremost caused by deregulation of HLA-I expression at the transcriptional and posttranscriptional level rather than structural alterations. The molecular mechanisms leading to the distinct HLA-I/APM component expression pattern in the various HNSCC samples requires in depth analysis, such as genomic sequencing and determination of the methylation status of different molecules. However, the results suggest that HNSCC employ distinct immune evasion strategies by affecting multiple components of the HLA class I antigen presentation pathway at different levels.

Interestingly, while the HLA-APM phenotypes were equally distributed over the UICC T stages, they were associated with a distinct TME regarding the type, density and spatial distribution of infiltrating immune cells. As expected, a correlation of HLA-I/APM expression with the immune cell infiltrate demonstrated a direct link of high intra-tumoral CD8 ${ }^{+} \mathrm{T}$ cell infiltration with high levels of HLA-I APM component and HLA-I surface expression. In detail, the mechanistic link is, at least in part, IFN- $\gamma$ expression as shown by us in the positive correlation of the intra-tumoral $\mathrm{CD}^{+} \mathrm{T}$ cell density to JAK1 expression, used as a surrogate marker for IFN- $\gamma$ signaling / inducibility. When looking at results from our HNSCC cell lines, we found constitutive, but rather low mRNA levels of HLA-I APM components, which could be enhanced upon IFN- $\gamma$ treatment, as it has been shown previously [5]. This underpins the hypothesis that a deregulation rather than structural alterations of these molecules might be responsible for the altered HLA-I/APM component expression in OSCC tumors. In this context, it is important to consider that the striking difference between the HLAI/APM phenotypes might be linked to the FOXP3:CD8 ratio, which was more than threefold higher in phenotypes II and III compared to phenotype I.

Thus, our experimental data suggest that the immunological control of phenotype I tumors might be linked with the patients' outcome. Unexpectedly, the correlation of the HLA-I/APM phenotypes to clinical data revealed that the HLA-I high/APMigh subgroup despite a high intra-tumoral $\mathrm{CD}^{+}$frequency and a rather low FOXP3:CD8 ${ }^{+}$ratio had an adverse outcome, which was most prevalent in T-stage 2 disease. Yet, most likely due to their overall excellent prognosis, this effect was not detected in T1 tumors. This is in line with a number of studies demonstrating a link of high levels of $\beta_{2}-\mathrm{m}$ to a poor prognosis [46,47]. Experimental models also suggest that an increased migration and invasion of OSCC cells is the reason for this survival disadvantage [48]. Assuming that the high 
levels of HLA-I HC and $\beta_{2}-\mathrm{m}$ in the phenotype I OSCC tumors might be often due to the IFN- $\gamma$ secretion of $\mathrm{T}$ cells, an explanation for the adverse patients' outcome might be caused by a systemic exhaustion leading to dysfunctional T cells both in blood and in the TME as described by others [49]. It is noteworthy that in our study the functionality of intra-tumoral $\mathrm{T}$ cells was not analyzed, since we primarily focused on the HLA-I/APM expression patterns. In contrast to the general dogma, patients with a HLA-Idiscordant high/low phenotype had a significant better prognosis compared to the HLA-Ihigh phenotype, which is in line with a report in CRC, in which HLA-A2-positive patients had a poorer tumor differentiation [50]. However, in our study this finding was limited to UICC T-stage 2 tumors suggesting that the tumor burden might play a key role in the stage dependent immunological control of OSCC. Last but not least, oxygenization of the TME might help in explaining our results. It was described in OSCC that a hypoxic microenvironment results in a hypoxic gene signature, which negatively interferes with immune surveillance and is associated with a poor clinical outcome. This might be of prognostic relevance in early stage OSCC, as recently demonstrated for colorectal cancer [51,52]. However, the exact underlying molecular mechanisms remains to be identified.

Next to melanoma, non-small cell lung cancer and CRC, in which a relationship between immune cell activity, HLA-I antigens, clinical outcome as well as response to CPI has been proven $[18,37,53]$, our group has shown a significant prognostic value of the presence and quantity of tumor infiltrating lymphocytes (TIL) in OSCC [32]. We propose that beyond the established cumulative suppression index including the parameters CD8, FOXP3 distance to CD8 and PD-L1 expression, the score would has to be extended at least by the "HLA-I expression", since a significant adverse outcome in tumors with a HLA-I ${ }^{\text {high}} / \mathrm{APM}^{\text {high }}$ phenotype and high intra-tumoral CD8 ${ }^{+}$cell content was found.

In conclusion, we state that a multifactorial tumor protecting microenvironment rather than a only a reduced HLA-I/APM expression determines the outcome of OSCC especially in early T stages of this disease. This hypothesis is based on the fact that neither the intra-tumoral CD8 ${ }^{+}$cell content nor the downregulation of HLA-I alone predict outcome especially in limited tumor disease. These data conclusively emphasize that there might exist a plethora of other soluble and physical factors or immune cells negatively interfering with the OSCC patients' responses to immunotherapy.

\section{Materials and Methods}

\subsection{Basic patient's characteristics, inclusion criteria and study approval}

The basal patient's cohort consists of 246 consecutive untreated OSCC patients who either had the initial biopsy and / or were treated with surgery at the Department of Oral and Maxillofacial Surgery, University Hospital Halle (Saale), Germany collected between 1995 and 2014. The cohort underwent surgical procedure and in all cases, the resection of the primary OSCC was done in combination with a neck dissection. Here, ipsilateral to the site of primary tumor levels $1-5$ were dissected, contralateral the levels 1 and 2 . The resection margins were $1 \mathrm{~cm}$ in all dimensions. Dependent on UICC stage an adjuvant radio-/radiochemotherapy was added.

The study was carried out in compliance with the Helsinki Declaration and was approved by the Ethics Committee of the Medical Faculty of the Martin Luther University Halle-Wittenberg (study \# 2017-81 and 2020-103). All cases had written consensus of patients. 72 cases were omitted from the study due to the dimension of suitable FFPE tissue or to insufficient tissue quality. All remaining tissue samples were tested for HPV association by either p16 IHC (Zeta Corp., Clone G175-405, dilution 1:25) and/or HPV PCR (Zytovision HPV Chip 1.0). 17 patients were omitted from the study because of a positive HPV status resulting in 160 cases for analyses.

With latest update of the cohort on July $1^{\text {st }} 2020$, after a median follow-up time of 27 months, $53 \%$ of the cohort (85 patients) had deceased with a median survival time at 22 months (mean 16 months). The basic clinical and histopathological data, therapeutic regimens and their association with OS were summarized in Table 1A and 1B. The tumors were classified as T stage $1(n=32 ; 20 \%)$, $2(49 ; 31 \%), 3(24 ; 15 \%)$ and $4(55 ; 34 \%)$ with and without nodal or distant metastasis. 


\subsection{Standard and multiplex immunohistochemistry}

Immunohistochemical analyses of tissue samples were performed as recently described [32]. Briefly, FFPE tissue probes were incubated with the following primary mAbs: NAMB ( $\beta_{2}-\mathrm{m}$; SP09-36; dilution 1:50), HC10 (against free HC of HLA-B and -C molecules; HSP09-35; 1:2500), NOB1 (TAP1; SP12-156; 1:50), NOB2 (TAP2; SP12-157; 1:50), SY-1 (LMP2; SP08-118; 1:200), TO-7 (LMP10; SP08-225; 1:200) and 6G4 (JAK1; Cell Signaling; 1:100). To determine, whether biologically active ( $\beta_{2}$-m-bound) HLA-A/B/C complex was expressed on OSCC, we performed IHC on fresh frozen tumor tissues of 10 exemplary cases was performed using the $\mathrm{W} 6 / 32 \mathrm{mAb}$ recognizing the HLA-A, $-\mathrm{B}$ and $-\mathrm{C} \mathrm{HC} / \beta_{2-}$ $\mathrm{m}$ antigen complex (dilution 1:10) [36]. After fixation with formalin for 3 minutes followed by a washing step the specimens were incubated with the primary antibody for 30 minutes, a post-block reagent for 20 minutes and a HRP polymer for 30 minutes all at room temperature with a washing step in between. Visualization was done with DAB and hemalaun as described above.

Immunohistochemistry (IHC) results were semi-quantitatively evaluated utilizing the immune reactive score (IRS) as described by Remmele et al. [35]. In short, for evaluation of membranous, cytoplasmic and nuclear staining intensity (0-negative, 1-low, 2-moderate, 3-strong positive) as well as percentage of stained cells (0-negative, $1-<10 \%, 2-10-50 \%, 3-51-80 \%, 4->80 \%$ ) were evaluated and the IRS then calculated as the product of both ranging from 0-12. .Ten percent of all cases plus all cases presenting any technical challenges were independently evaluated by two pathologists (CW, DB) and co-reviewed to harmonize and ensure reproducibility of the scoring. One pathologist (DB) scored all the remaining cases.

For correlation analyses of the expression of HLA-I and APM components with the frequency and localization of immune cell subpopulations within the tumor, multispectral imaging data from the same patient cohort ( $\mathrm{n}=108$ with immune cell data) previously published by us were employed [32].

\subsection{Definition of the HLA-I/APM phenotypes}

Based on the HLA-I (HC/ $\left.\beta_{2}-\mathrm{m}\right)$ and APM (TAP, LMP) component expression pattern, OSCC were categorized into four distinct HLA/APM phenotypes. In detail, based on the median IRS of membranous HLA-I HC and $\beta_{2}$-m expression, HLA expression was dichotomized in "HLA-I high" (median $\geq 4$ ) and "HLA-I low" (median $\leq 3$ ). Based on the median IRS of cytoplasmic TAP1 and TAP2 as well as the median IRS of nuclear LMP2 and LMP10, APM expression was dichotomized in "APM high" (median $\geq 4$ ) and "APM low" (median $\leq 3$ ). As a consequence, four distinct phenotypes (I-IV) could be defined: (i) phenotype I expressed high levels of both the HLA-I HC/ $\beta_{2}-\mathrm{m}$ and APM components ("HLA-I ${ }^{\text {high} / A P M} \mathbf{M}^{\text {high") }}$, (ii) phenotype II displayed a low expression pattern of both HC/ $/ \beta_{2}-\mathrm{m}$ and APM components ("HLA-Ilow/APM ${ }^{\text {low") }}$ ), (iii) phenotype III expressed discordant levels of HLA-I HC/ $\beta_{2}-\mathrm{m}$ (HLA ${ }^{\text {high/low }}$ or HLA ${ }^{\text {low/high }}$ ) and high levels of APM components ("HLA-Idiscordant high/low/APM ${ }^{\text {high") }}$ and phenotype IV displayed discordant levels of HLA-I HC/ $\beta_{2}-m$ (HLA ${ }^{\text {high/low }}$ or HLA $^{\text {low/high }}$ ) and low APM levels (“HLA-Idiscordant high/low/APM $\left.{ }^{\text {low” }}\right)$.

\subsection{Bioinformatics}

In silico analysis was performed using the R2 web tool (http://r2.amc.nl) in order to predict the correlation of HLA-I APM components, CD4, CD8, CD274 and FoxP3 with the mRNA expression of the different genes in HPV- head and neck cancer (HNC) patients. For this, the TCGA data set "Tumor head and neck squamous cell carcinoma" was chosen $(n=520)$. $\mathrm{HPV}^{+} \mathrm{HNC}$ patients and patients with unknown HPV status were omitted from the calculations, while HPV- HNC patients (hpv_status_p16-negative, 103 patients) with data available for the respective markers were analyzed. The $2 \log$ expression ratio was compared and a linear regression was calculated. A p-value $<1 \mathrm{e}^{-3}$ was considered as significant.

For the OS analyses, the XENA database (https://xenabrowser.net) was employed for the TCGA Head and Neck Cancer study $(\mathrm{n}=604)$. Only primary tumor samples from HPV- patients (hpv_status_p16-negative, 103 patients) were included. A p-value $<0.1$ was considered as significant. 


\subsection{Statistical analyses}

To evaluate the relationship between HLA-I/APM expression, tumor stage and outcome two groups (low vs. high protein expression levels) were selected for each marker based on an even distribution of patient numbers in these groups. Cox's regression hazard model and Kaplan-Meier analyses were used to estimate a correlation of HLA-I and APM expression with OS of OSCC patients. The Cox model was adjusted for prognostic effect of co-variables ( $\mathrm{T}$ stage, $\mathrm{N}$ stage and grading), and relative risk (RR) was calculated. The OS was calculated from the day of histological tumor diagnosis until the date of last follow-up or (if applicable) death. The interrelationships between the different HLA-I antigens and APM components were tested with the Spearman's rank correlation $\left(r_{s}\right.$, correlation coefficient). Multiple hypotheses corrections were not applied._A probability $(p)$ of $<0.05$ was defined as a significant result and marked with a star (or if lower than 0.01 with two stars). If not otherwise specified, the results from the cell culture experiments were expressed as mean of at least three biological replicates including standard deviation. All statistical analyses were performed using SPSS software version 20.0 (SPSS Inc., Chicago, USA) and Microsoft Excel 2010 (Microsoft Corporation). For the t-test, two samples assuming unequal variances have been selected.

\subsection{In vitro induction of HLA-I/APM expression}

For determination of the constitutive and IFN- $\gamma$ inducible HLA-I/APM expression in vitro, the human head and neck squamous cell carcinoma (HNSCC) cell lines SAS, Cal33 and FaDu were cultured in RPMI medium supplemented with $10 \%$ (v/v) fetal calf serum (PAN, Germany), 2 mM Lglutamine, 100 units $/ \mathrm{ml}$ penicillin, and $100 \mu \mathrm{g} / \mathrm{ml}$ streptomycin at $37{ }^{\circ} \mathrm{C}$ in $5 \%(\mathrm{v} / \mathrm{v}) \mathrm{CO}_{2}$ humidified air and were left untreated or treated for 24 or $48 \mathrm{hrs}$ with recombinant interferon (IFN) $\gamma(200 \mu \mathrm{g} / \mathrm{ml})$. Analysis was performed either directly or employing cell pellets, stored in liquid nitrogen until further use.

\subsection{RNA isolation, semi-quantitative and quantitative PCR}

For evaluation of HLA-I/APM expression by the tumor cell lines as well as by a subcollective of OSCC with availability of FFPE and fresh frozen sections and specimens of normal oral mucosa total RNA was extracted using the NucleoSpin RNA extraction kit (Macherey-Nagel) according to the manufacturer's instructions and converted to cDNA using the cDNA synthesis kit and oligo-dT primer from Thermo Scientific. Target-specific primers (Supplementary Table 2) have been already described [8]. PCR was performed in a Rotorgene and using the Rotorgene $6000^{\mathrm{TM}}$ series software (Qiagen, Hilden, Germany) using GAPDH as control and for normalization.

cDNA was synthesized from double DNase I digested total RNA (500 ng) using RevertAid ${ }^{\mathrm{TM}} \mathrm{H}$ Minus First Strand cDNA synthesis kit (Fermentas, St. Ingbert, Germany). Thereafter, qRT-PCR was performed on Rotorgene 6000 (Qiagen) with a two-step protocol (40 cycles; $95{ }^{\circ} \mathrm{C}, 15 \mathrm{~s} ; 60{ }^{\circ} \mathrm{C}, 30 \mathrm{~s}$ ) using target-specific primers in combination with Platinum ${ }^{\circledR}$ SYBR ${ }^{\circ}$ Green qPCR SuperMix-UDG (Invitrogen, Karlsruhe, Germany). Relative mRNA expression levels for specific genes were normalized to that of the housekeeping gene delta-aminolevulinate synthase (ALAS) 1. For determination the IFN- $\gamma$ inducibility, the mRNA levels of untreated HNSCC cell lines were set to one and differences to expression levels of IFN- $\gamma$-treated cells were calculated. qPCR analyses were performed on samples obtained from three independent experiments.

\subsection{Western blot analyses}

Proteins were extracted from $1 \times 10^{7}$ cells from the three HNSCC cell lines and protein concentration was determined with the Pierce BCA protein assay kit (Fisher Scientific, Schwerte, Germany). For Western blot analyses, $50 \mu \mathrm{g}$ protein/lane was separated on $8 \%-12 \%$ SDS-PAGEs, transferred onto nitrocellulose membranes (Schleicher \& Schuell, Dassel, Germany), and stained with $(3 \%, \mathrm{w} / \mathrm{v})$ Ponceau S. Immunodetection was performed with specific primary mAbs directed against TAP1, TAP2, LMP2, LMP10, HLA-I HC and $\beta_{2}-\mathrm{m}$ (kindly provided by S. Ferrone, Harvard, Boston, USA) as recently described [8]. Staining of blots with a GAPDH mAb (Cell Signaling, Frankfurt, 
Germany) served as loading control. As secondary antibodies the horseradish peroxidase (HRP)conjugated anti-rabbit and anti-mouse antibodies (DAKO, Hamburg, Germany), respectively, were used and the LumiLight WB substrate (Roche Diagnostics, Mannheim, Germany) was employed for detection and visualization with a CCD camera (Eastman Kodak Co., Berlin, Germany).

\subsection{Flow cytometry}

Flow cytometric analyses were performed on a BD LSRFortessa unit (Becton Dickinson, Biosciences, Heidelberg, Germany). Briefly, $5 \times 10^{5}$ cells left untreated or treated with 200 units $/ \mathrm{ml}$ of recombinant IFN- $\gamma$ for $48 \mathrm{hrs}$ were washed twice in PBS followed by direct staining with the fluorescein isothiocyanate (FITC)-labeled mouse anti-human HLA-I mAb (W6/32) and the respective isotype control (Beckman Coulter, Krefeld, Germany) and then measured on a flow cytometer. For data evaluation, the Kaluza software (Beckman Coulter) was applied. The results are expressed as mean specific fluorescence intensity (MFI) obtained from at least three independent experiments.

\section{Conclusions}

Immunotherapy is a promising tool for the treatment of different malignancies. However, the survival benefit is limited to a subset of patients. A better understanding of the complex interactions between tumor cells and the tumor microenvironment is urgently needed to improve overall response for cancer patients and improve prognosis towards long-term outcome under immunotherapy.

In this study, of the HLA-I and APM component expression was analyzed in a large cohort of OSCC tissues and correlated to the intra-tumoral immune cell infiltrate. These findings were associated to the clinical data of the patients. Unexpectedly, despite a high intra-tumoral $\mathrm{CD}^{+} \mathrm{T}$ cell content, tumors with high expression levels of HLA-I and APM components presented a rather unfavorable outcome, which was most significant in smaller (T1/T2) tumors. We conclude that an effective immunomodulatory treatment strategy in OSCC has to include the blockade of more than one immune regulatory axis.

Supplementary Materials: The following are available online at www.mdpi.com/xxx/s1, Figure S1: In silico correlation of CD8 mRNA expression with HLA-A, $\beta 2-\mathrm{m}$ and APM components, Figure S2: Constitutive and IFN- $\gamma$ mediated upregulation of HLA-I APM component expression in HNSCC cell lines. Table S1: Concordant membranous HLA-I HC and $\beta 2$-m expression with HLA-I surface expression in FFPE vs. frozen OSCC lesions, Table S2: Primers used for analyses of HLA-I and APM component expression, Video S1: title.

Author Contributions: Barbara Seliger and Claudia Wickenhauser designed and supervised the project as well as analyzed and interpreted the results. Jana Beer and Daniel Bethmann performed the immunohistochemistry. Daniel Bethmann and Claudia Wickenhauser evaluated the immunohistochemistry. Jürgen Bukur performed the cell culture and flow cytometry experiments. Jürgen Bukur and Barbara Seliger evaluated the cell culture and flow cytometry experiments. André Steven performed the TCGA data acquisition and interpretation. Alexander Eckert and Matthias Kappler provided the fresh frozen OSCC samples and they collected the clinical data together with Daniel Bethmann. All authors participated in data analysis. Bernard Fox edited the manuscript, discussed the results and was involved in the MSI data generation and interpretation. Claudia Wickenhauser, Barbara Seliger and Daniel Bethmann drafted the manuscript.

Funding: This work was sponsored by the Deutsche Forschungsgemeinschaft project DFG 585/22-1 (BS) and the Mildred Scheel Foundation grants 110703 and 111091 (BS).

Acknowledgments: We would like to thank Nicole Ott and Maria Heise from the Institute of Immunology for excellent secretarial help. Claudia Wickenhauser and Daniel Bethmann would like to thank the members of the Institute of Pathology`s, histology laboratory for their comprehensive help in this study.

Conflicts of Interest: BAF discloses consulting activities and/or research support related to multiplex IHC from Akoya Biosciences/PerkinElmer, Bristol-Myers Squibb, Definiens/AstraZeneca, Macrogenics, OncoSec and Ultivue. The remaining authors declare that there exist no conflicts of interest for any of the authors. 
Ethics approval: The study was approved by the Ethics Committee of the Medical Faculty of the Martin Luther University Halle-Wittenberg, Halle, Germany (\#2017-81).

\section{List of abbreviations}

ALAS 1, delta-aminolevulinate synthase 1; APM, antigen processing machinery; $\beta 2-\mathrm{m}$, beta-2-microglobulin; CPI, checkpoint inhibitor; CRC, colorectal cancer; CSI, cumulative suppression index; CTL, cytotoxic T lymphocyte; DAB, 3,3'-diaminobenzidine; FFPE, formalin-fixed paraffin-embedded; FITC, fluorescein isothiocyanate; FoxP3, Fork head-Box-Protein P3; GAPDH, glyceraldehyde-3-phosphate dehydrogenase; HC, heavy chain; HLA, human leukocyte antigen; HLA-I, human leukocyte antigen class I; HNC, head and neck cancer; HNSCC, head and neck squamous cell carcinoma; HPV, human papilloma virus; HRP, horseradish peroxidase; IFN, interferon; IHC, immunohistochemistry; IM, invasive margin; IRS, international rating score; LMP, low molecular weight protein; $\mathrm{mAb}$, monoclonal antibody; MFI, mean specific fluorescence intensity; MSI, multispectral imaging; OS, overall survival; OSCC, oral squamous cell carcinoma; PBMC, peripheral blood mononuclear cells; PCR, polymerase chain reaction; PD-L1, programmed death-like receptor ligand 1; ROC curves, Receiver-Operating-Characteristic curves; RR, relative risk; RT, room temperature; STAT, signal transducer and activator of transcription; TA, tumor antigen; TAM, tumor associated macrophages; TAP, transporter associated with antigen processing; TC, tumor center; TCGA, The Cancer Genome Atlas; TIL, tumor infiltrating lymphocyte; TME, tumor microenvironment; Treg, regulatory $\mathrm{T}$ cell; TSA, tyramide signal amplification; UICC, Union Internationale Contre le Cancer.

\section{References}

1. Tuccitto, A.; Shahaj, E.; Vergani, E.; Ferro, S.; Huber, V.; Rodolfo, M.; Castelli, C.; Rivoltini, L.; Vallacchi, V. Immunosuppressive circuits in tumor microenvironment and their influence on cancer treatment efficacy. Virchows Archiv : an international journal of pathology 2019, 474, 407420, doi:10.1007/s00428-018-2477-z.

2. Draghi, A.; Chamberlain, C.A.; Furness, A.; Donia, M. Acquired resistance to cancer immunotherapy. Seminars in immunopathology 2019, 41, 31-40, doi:10.1007/s00281-018-0692-y.

3. Kim, T.K.; Herbst, R.S.; Chen, L. Defining and Understanding Adaptive Resistance in Cancer Immunotherapy. Trends Immunol 2018, 39, 624-631, doi:10.1016/j.it.2018.05.001.

4. Fridman, W.H.; Zitvogel, L.; Sautes-Fridman, C.; Kroemer, G. The immune contexture in cancer prognosis and treatment. Nat Rev Clin Oncol 2017, 14, 717-734, doi:10.1038/nrclinonc.2017.101.

5. Mandal, R.; Senbabaoglu, Y.; Desrichard, A.; Havel, J.J.; Dalin, M.G.; Riaz, N.; Lee, K.W.; Ganly, I.; Hakimi, A.A.; Chan, T.A., et al. The head and neck cancer immune landscape and its immunotherapeutic implications. JCI Insight 2016, 1, e89829, doi:10.1172/jci.insight.89829.

6. Moy, J.D.; Moskovitz, J.M.; Ferris, R.L. Biological mechanisms of immune escape and implications for immunotherapy in head and neck squamous cell carcinoma. Eur J Cancer 2017, 76, 152-166, doi:10.1016/j.ejca.2016.12.035.

7. Concha-Benavente, F.; Srivastava, R.; Ferrone, S.; Ferris, R.L. Immunological and clinical significance of HLA class I antigen processing machinery component defects in malignant cells. Oral Oncol 2016, 58, 52-58, doi:10.1016/j.oraloncology.2016.05.008.

8. Respa, A.; Bukur, J.; Ferrone, S.; Pawelec, G.; Zhao, Y.; Wang, E.; Marincola, F.M.; Seliger, B. Association of IFN-gamma signal transduction defects with impaired HLA class I antigen processing in melanoma cell lines. Clin Cancer Res 2011, 17, 2668-2678, doi:10.1158/10780432.CCR-10-2114.

9. Seliger, B. Novel insights into the molecular mechanisms of HLA class I abnormalities. Cancer Immunol Immunother 2012, 61, 249-254, doi:10.1007/s00262-011-1153-9. 
10. McGranahan, N.; Rosenthal, R.; Hiley, C.T.; Rowan, A.J.; Watkins, T.B.K.; Wilson, G.A.; Birkbak, N.J.; Veeriah, S.; Van Loo, P.; Herrero, J., et al. Allele-Specific HLA Loss and Immune Escape in Lung Cancer Evolution. Cell 2017, 171, 1259-1271 e1211, doi:10.1016/j.cell.2017.10.001.

11. Chowell, D.; Morris, L.G.T.; Grigg, C.M.; Weber, J.K.; Samstein, R.M.; Makarov, V.; Kuo, F.; Kendall, S.M.; Requena, D.; Riaz, N., et al. Patient HLA class I genotype influences cancer response to checkpoint blockade immunotherapy. Science 2018, 359, 582-587, doi:10.1126/science.aao4572.

12. Shukla, S.A.; Rooney, M.S.; Rajasagi, M.; Tiao, G.; Dixon, P.M.; Lawrence, M.S.; Stevens, J.; Lane, W.J.; Dellagatta, J.L.; Steelman, S., et al. Comprehensive analysis of cancer-associated somatic mutations in class I HLA genes. Nature biotechnology 2015, 33, 1152-1158, doi:10.1038/nbt.3344.

13. Eichmuller, S.B.; Osen, W.; Mandelboim, O.; Seliger, B. Immune Modulatory microRNAs Involved in Tumor Attack and Tumor Immune Escape. J Natl Cancer Inst 2017, 109, doi:10.1093/jnci/djx034.

14. Pages, F.; Mlecnik, B.; Marliot, F.; Bindea, G.; Ou, F.S.; Bifulco, C.; Lugli, A.; Zlobec, I.; Rau, T.T.; Berger, M.D., et al. International validation of the consensus Immunoscore for the classification of colon cancer: a prognostic and accuracy study. Lancet 2018, 391, 2128-2139, doi:10.1016/S0140-6736(18)30789-X.

15. Andersen, R.; Westergaard, M.C.W.; Kjeldsen, J.W.; Muller, A.; Pedersen, N.W.; Hadrup, S.R.; Met, O.; Seliger, B.; Kromann-Andersen, B.; Hasselager, T., et al. T-cell Responses in the Microenvironment of Primary Renal Cell Carcinoma-Implications for Adoptive Cell Therapy. Cancer Immunol Res 2018, 6, 222-235, doi:10.1158/2326-6066.CIR-17-0467.

16. Shin, D.S.; Zaretsky, J.M.; Escuin-Ordinas, H.; Garcia-Diaz, A.; Hu-Lieskovan, S.; Kalbasi, A.; Grasso, C.S.; Hugo, W.; Sandoval, S.; Torrejon, D.Y., et al. Primary Resistance to PD-1 Blockade Mediated by JAK1/2 Mutations. Cancer Discov 2017, 7, 188-201, doi:10.1158/21598290.CD-16-1223.

17. Zaretsky, J.M.; Garcia-Diaz, A.; Shin, D.S.; Escuin-Ordinas, H.; Hugo, W.; Hu-Lieskovan, S.; Torrejon, D.Y.; Abril-Rodriguez, G.; Sandoval, S.; Barthly, L., et al. Mutations Associated with Acquired Resistance to PD-1 Blockade in Melanoma. N Engl J Med 2016, 375, 819-829, doi:10.1056/NEJMoa1604958.

18. Perea, F.; Bernal, M.; Sanchez-Palencia, A.; Carretero, J.; Torres, C.; Bayarri, C.; GomezMorales, M.; Garrido, F.; Ruiz-Cabello, F. The absence of HLA class I expression in non-small cell lung cancer correlates with the tumor tissue structure and the pattern of $\mathrm{T}$ cell infiltration. Int J Cancer 2017, 140, 888-899, doi:10.1002/ijc.30489.

19. Cohen, E.E.W.; Bell, R.B.; Bifulco, C.B.; Burtness, B.; Gillison, M.L.; Harrington, K.J.; Le, Q.T.; Lee, N.Y.; Leidner, R.; Lewis, R.L., et al. The Society for Immunotherapy of Cancer consensus statement on immunotherapy for the treatment of squamous cell carcinoma of the head and neck (HNSCC). J Immunother Cancer 2019, 7, 184, doi:10.1186/s40425-019-0662-5.

20. Pulte, D.; Brenner, H. Changes in survival in head and neck cancers in the late 20th and early 21st century: a period analysis. Oncologist 2010, 15, 994-1001, doi:10.1634/theoncologist.20090289. 
21. Zini, A.; Czerninski, R.; Sgan-Cohen, H.D. Oral cancer over four decades: epidemiology, trends, histology, and survival by anatomical sites. J Oral Pathol Med 2010, 39, 299-305, doi:10.1111/j.1600-0714.2009.00845.x.

22. Husain, N.; Neyaz, A. Human papillomavirus associated head and neck squamous cell carcinoma: Controversies and new concepts. J Oral Biol Craniofac Res 2017, 7, 198-205, doi:10.1016/j.jobcr.2017.08.003.

23. Omura, K. Current status of oral cancer treatment strategies: surgical treatments for oral squamous cell carcinoma. Int J Clin Oncol 2014, 19, 423-430, doi:10.1007/s10147-014-0689-z.

24. Chow, L.Q.M.; Haddad, R.; Gupta, S.; Mahipal, A.; Mehra, R.; Tahara, M.; Berger, R.; Eder, J.P.; Burtness, B.; Lee, S.H., et al. Antitumor Activity of Pembrolizumab in BiomarkerUnselected Patients With Recurrent and/or Metastatic Head and Neck Squamous Cell Carcinoma: Results From the Phase Ib KEYNOTE-012 Expansion Cohort. J Clin Oncol 2016, 34, 3838-3845, doi:10.1200/JCO.2016.68.1478.

25. Ferris, R.L.; Licitra, L.; Fayette, J.; Even, C.; Blumenschein, G.R.; Harrington, K.J.; Guigay, J.; Vokes, E.E.; Saba, N.F.; Haddad, R.I., et al. Nivolumab in Patients With Recurrent or Metastatic Squamous Cell Carcinoma of the Head and Neck: Efficacy and Safety in CheckMate 141 by Prior Cetuximab Use. Clin Cancer Res 2019, 10.1158/1078-0432.CCR-183944, doi:10.1158/1078-0432.CCR-18-3944.

26. Haddad, R.; Concha-Benavente, F.; Blumenschein, G., Jr.; Fayette, J.; Guigay, J.; Colevas, A.D.; Licitra, L.; Kasper, S.; Vokes, E.E.; Worden, F., et al. Nivolumab treatment beyond RECISTdefined progression in recurrent or metastatic squamous cell carcinoma of the head and neck in CheckMate 141: A subgroup analysis of a randomized phase 3 clinical trial. Cancer 2019, 10.1002/cncr.32190, doi:10.1002/cncr.32190.

27. Cavalieri, S.; Rivoltini, L.; Bergamini, C.; Locati, L.D.; Licitra, L.; Bossi, P. Immuno-oncology in head and neck squamous cell cancers: News from clinical trials, emerging predictive factors and unmet needs. Cancer treatment reviews 2018, 65, 78-86, doi:10.1016/j.ctrv.2018.03.003.

28. Foy, J.P.; Bertolus, C.; Michallet, M.C.; Deneuve, S.; Incitti, R.; Bendriss-Vermare, N.; Albaret, M.A.; Ortiz-Cuaran, S.; Thomas, E.; Colombe, A., et al. The immune microenvironment of HPV-negative oral squamous cell carcinoma from never-smokers and never-drinkers patients suggests higher clinical benefit of IDO1 and PD1/PD-L1 blockade. Ann Oncol 2017, 28, 1934-1941, doi:10.1093/annonc/mdx210.

29. Galon, J.; Costes, A.; Sanchez-Cabo, F.; Kirilovsky, A.; Mlecnik, B.; Lagorce-Pages, C.; Tosolini, M.; Camus, M.; Berger, A.; Wind, P., et al. Type, density, and location of immune cells within human colorectal tumors predict clinical outcome. Science 2006, 313, 1960-1964, doi:10.1126/science.1129139.

30. Mlecnik, B.; Bindea, G.; Angell, H.K.; Maby, P.; Angelova, M.; Tougeron, D.; Church, S.E.; Lafontaine, L.; Fischer, M.; Fredriksen, T., et al. Integrative Analyses of Colorectal Cancer Show Immunoscore Is a Stronger Predictor of Patient Survival Than Microsatellite Instability. Immunity 2016, 44, 698-711, doi:10.1016/j.immuni.2016.02.025.

31. Herbst, R.S.; Soria, J.C.; Kowanetz, M.; Fine, G.D.; Hamid, O.; Gordon, M.S.; Sosman, J.A.; McDermott, D.F.; Powderly, J.D.; Gettinger, S.N., et al. Predictive correlates of response to 
the anti-PD-L1 antibody MPDL3280A in cancer patients. Nature 2014, 515, 563-567, doi:10.1038/nature14011.

32. Feng, Z.; Bethmann, D.; Kappler, M.; Ballesteros-Merino, C.; Eckert, A.; Bell, R.B.; Cheng, A.; Bui, T.; Leidner, R.; Urba, W.J., et al. Multiparametric immune profiling in HPV- oral squamous cell cancer. JCI Insight 2017, 2, doi:10.1172/jci.insight.93652.

33. Horton, J.D.; Knochelmann, H.M.; Day, T.A.; Paulos, C.M.; Neskey, D.M. Immune Evasion by Head and Neck Cancer: Foundations for Combination Therapy. Trends in cancer 2019, 5 , 208-232, doi:10.1016/j.trecan.2019.02.007.

34. Muller, S. Update from the 4th Edition of the World Health Organization of Head and Neck Tumours: Tumours of the Oral Cavity and Mobile Tongue. Head and neck pathology 2017, 11, 33-40, doi:10.1007/s12105-017-0792-3.

35. Remmele, W.; Stegner, H.E. [Recommendation for uniform definition of an immunoreactive score (IRS) for immunohistochemical estrogen receptor detection (ER-ICA) in breast cancer tissue]. Pathologe 1987, 8, 138-140.

36. Stam, N.J.; Vroom, T.M.; Peters, P.J.; Pastoors, E.B.; Ploegh, H.L. HLA-A- and HLA-B-specific monoclonal antibodies reactive with free heavy chains in western blots, in formalin-fixed, paraffin-embedded tissue sections and in cryo-immuno-electron microscopy. Int Immunol 1990, 2, 113-125.

37. Smyth, M.J.; Ngiow, S.F.; Ribas, A.; Teng, M.W. Combination cancer immunotherapies tailored to the tumour microenvironment. Nat Rev Clin Oncol 2016, 13, 143-158, doi:10.1038/nrclinonc.2015.209.

38. Aptsiauri, N.; Ruiz-Cabello, F.; Garrido, F. The transition from HLA-I positive to HLA-I negative primary tumors: the road to escape from T-cell responses. Curr Opin Immunol 2018, 51, 123-132, doi:10.1016/j.coi.2018.03.006.

39. Paulson, K.G.; Voillet, V.; McAfee, M.S.; Hunter, D.S.; Wagener, F.D.; Perdicchio, M.; Valente, W.J.; Koelle, S.J.; Church, C.D.; Vandeven, N., et al. Acquired cancer resistance to combination immunotherapy from transcriptional loss of class I HLA. Nat Commun 2018, 9, 3868, doi:10.1038/s41467-018-06300-3.

40. Seliger, B. Molecular mechanisms of HLA class I-mediated immune evasion of human tumors and their role in resistance to immunotherapies. Hla 2016, 88, 213-220, doi:10.1111/tan.12898.

41. Botticelli, A.; Mezi, S.; Pomati, G.; Cerbelli, B.; Di Rocco, C.; Amirhassankhani, S.; Sirgiovanni, G.; Occhipinti, M.; Napoli, V.; Emiliani, A., et al. The 5-Ws of immunotherapy in head and neck cancer. Crit Rev Oncol Hematol 2020, 153, 103041, doi:10.1016/j.critrevonc.2020.103041.

42. Krishna, S.; Ulrich, P.; Wilson, E.; Parikh, F.; Narang, P.; Yang, S.; Read, A.K.; Kim-Schulze, S.; Park, J.G.; Posner, M., et al. Human Papilloma Virus Specific Immunogenicity and Dysfunction of CD8(+) T Cells in Head and Neck Cancer. Cancer Res 2018, 78, 6159-6170, doi:10.1158/0008-5472.CAN-18-0163.

43. Gettinger, S.; Choi, J.; Hastings, K.; Truini, A.; Datar, I.; Sowell, R.; Wurtz, A.; Dong, W.; Cai, G.; Melnick, M.A., et al. Impaired HLA Class I Antigen Processing and Presentation as a Mechanism of Acquired Resistance to Immune Checkpoint Inhibitors in Lung Cancer. Cancer Discov 2017, 7, 1420-1435, doi:10.1158/2159-8290.CD-17-0593. 
44. Cai, L.; Michelakos, T.; Yamada, T.; Fan, S.; Wang, X.; Schwab, J.H.; Ferrone, C.R.; Ferrone, S. Defective HLA class I antigen processing machinery in cancer. Cancer Immunol Immunother 2018, 67, 999-1009, doi:10.1007/s00262-018-2131-2.

45. Spranger, S.; Luke, J.J.; Bao, R.; Zha, Y.; Hernandez, K.M.; Li, Y.; Gajewski, A.P.; Andrade, J.; Gajewski, T.F. Density of immunogenic antigens does not explain the presence or absence of the T-cell-inflamed tumor microenvironment in melanoma. Proc Natl Acad Sci U S A 2016, 113, E7759-E7768, doi:10.1073/pnas.1609376113.

46. Klein, T.; Levin, I.; Niska, A.; Koren, R.; Gal, R.; Schachter, J.; Kfir, B.; Narinski, R.; Warchaizer, S.; Klein, B. Correlation between tumour and serum beta $2 \mathrm{~m}$ expression in patients with breast cancer. Eur J Immunogenet 1996, 23, 417-423, doi:10.1111/j.1744-313x.1996.tb00132.x.

47. Tsimberidou, A.M.; Kantarjian, H.M.; Wen, S.; O'Brien, S.; Cortes, J.; Wierda, W.G.; Koller, C.; Pierce, S.; Brandt, M.; Freireich, E.J., et al. The prognostic significance of serum beta2 microglobulin levels in acute myeloid leukemia and prognostic scores predicting survival: analysis of 1,180 patients. Clin Cancer Res 2008, 14, 721-730, doi:10.1158/1078-0432.CCR-072063.

48. Chen, C.H.; Su, C.Y.; Chien, C.Y.; Huang, C.C.; Chuang, H.C.; Fang, F.M.; Huang, H.Y.; Chen, C.M.; Chiou, S.J. Overexpression of beta2-microglobulin is associated with poor survival in patients with oral cavity squamous cell carcinoma and contributes to oral cancer cell migration and invasion. Br J Cancer 2008, 99, 1453-1461, doi:10.1038/sj.bjc.6604698.

49. Ludwig, S.; Floros, T.; Theodoraki, M.N.; Hong, C.S.; Jackson, E.K.; Lang, S.; Whiteside, T.L. Suppression of Lymphocyte Functions by Plasma Exosomes Correlates with Disease Activity in Patients with Head and Neck Cancer. Clin Cancer Res 2017, 23, 4843-4854, doi:10.1158/10780432.CCR-16-2819.

50. Kiewe, P.; Mansmann, V.; Scheibenbogen, C.; Buhr, H.J.; Thiel, E.; Nagorsen, D. HLA-A2 expression, stage, and survival in colorectal cancer. International journal of colorectal disease 2008, 23, 767-772, doi:10.1007/s00384-008-0488-y.

51. Eckert, A.W.; Wickenhauser, C.; Salins, P.C.; Kappler, M.; Bukur, J.; Seliger, B. Clinical relevance of the tumor microenvironment and immune escape of oral squamous cell carcinoma. J Transl Med 2016, 14, 85, doi:10.1186/s12967-016-0828-6.

52. Zou, Y.F.; Rong, Y.M.; Tan, Y.X.; Xiao, J.; Yu, Z.L.; Chen, Y.F.; Ke, J.; Li, C.H.; Chen, X.; Wu, X.J., et al. A signature of hypoxia-related factors reveals functional dysregulation and robustly predicts clinical outcomes in stage I/II colorectal cancer patients. Cancer Cell Int 2019, 19, 243, doi:10.1186/s12935-019-0964-1.

53. Restifo, N.P.; Smyth, M.J.; Snyder, A. Acquired resistance to immunotherapy and future challenges. Nat Rev Cancer 2016, 16, 121-126, doi:10.1038/nrc.2016.2. 